\title{
Cinema e imaginário científico
}

\author{
Cinema and the \\ scientific imaginary
}

Bernardo Jefferson de Oliveira

Faculdade de Educação da Universidade Federal de Minas Gerais

Av. Antonio Carlos 6627 sala 2061, Pampulha

31270-901 Belo Horizonte - MG - Brasil

be@fae.ufmg.br
OLIVEIRA, B. J.: Cinema e imaginário científico.

História, Ciências, Saúde - Manguinhos, v. 13 (suplemento), p. 133-50, outubro 2006.

Este artigo explora alguns dos vínculos entre a ciência e o cinema: o uso de filmes como instrumento de observação, material didático de educação científica e, principalmente, meio de expressão e veículo formador do imaginário social acerca da ciência. Para tanto, retoma discussão conceitual sobre as noções de imaginário e representação social, busca delinear diferenciação de tipos de filmes e sintetizar algumas análises sobre imagens da prática científica e de estereótipos de cientistas. São apresentadas dificuldades na avaliação da influência do cinema no imaginário científico, mas defendida a importância de seu estudo para a história da ciência.

PALAVRAS-CHAVE: cinema; ciência; imaginário científico; ficção científica; história da ciência.

OLIVEIRA, B. J.: Cinema and the scientific imaginary.

História, Ciências, Saúde-Manguinhos, v. 13 (supplement), p. 133-50, October 2006.

The article examines some of the ties between science and cinema, for example, how movies can serve as a tool of observation, as teaching material in the field of science, and especially as a means of expressing and shaping the social imaginary of science. To this end, it takes up a conceptual discussion of the notions of 'imaginary' and 'social representation'. It also endeavors to sketch a differentiation between types of movies and to summarize some analyses of images of scientific practice and stereotypes of scientists. Although there are challenges in evaluating how movies have influenced the scientific imaginary, the study of this topic is important to the history of science.

KEYWORDS: cinema; science; scientific imaginary; science fiction; history of science. 
A vinculação entre cinema e ciência é antiga. Antes mesmo de os irmãos Lumière encantarem o público parisiense, em 1895, com a projeção de cenas impressionantes que inauguraram o cinema como uma fabulosa forma de entretenimento, as técnicas de criar imagens em movimento com seqüência de fotografias serviram a propósitos científicos. Duas décadas antes, o astrônomo francês Jules Janssen já usava um 'revólver fotográfico', para reproduzir o registro da trajetória do planeta Vênus através do disco solar. Inspirado em sua experiência, o fotógrafo inglês Edward Muybridge montou uma incrível seqüência de fotografias da corrida de um cavalo, reproduzindo seu movimento em detalhes. Isso foi logo percebido como um grande recurso para o estudo da fisiologia do movimento. A câmara, no formato de arma, foi aprimorada pelo fisiólogo francês Etienne-Jules Marey e permitia, sem dificuldade, mirar e acompanhar movimentos como, por exemplo, o de uma ave voando. Etude de la locomotion animale par la chrono-photographie de Marey foi publicado em 1887 (Nancy; Berger-Levrault, 1887) a partir das análises propiciadas por esse novo instrumento de pesquisa. Cientistas de outras áreas não tardaram a perceber as vantagens desse recurso e utilizá-lo. Algumas dessas experiências com 'rolos de cronofotografias' foram mostradas na Academia de Ciências da França, no final da década de 1880.

Embora tenha se tornado uma forma de entretenimento e galgado o status de um gênero artístico próprio, a sétima arte, o registro cinematográfico continuou a servir como instrumento científico. Uma ferramenta que possibilitava vários tipos de experimentos e o registro de ocorrências em condições inóspitas ou não discerníveis a olho nu, permitindo observações repetidas e análises detalhadas, com a separação de instantes.

A vivacidade das imagens e sua reprodutibilidade facilitaram sua aceitação como pura representação da realidade. Mesmo sabendo que são montadas, a magia e o encantamento do fluxo de imagens fazem o espectador reagir como se fosse a própria realidade. Cenas filmadas foram rapidamente aceitas como provas materiais, testemunhos insuspeitos e até evidências científicas. Nossa distância temporal desse processo de legitimação certamente contribui para vermos essa utilização como óbvia e natural. Se hoje em dia os experimentos virtuais realizados em computadores ainda geram polêmica sobre sua validade no processo de verificação de hipóteses, o registro em filmes de eventos já não deixa dúvidas.

Na historiografia da ciência, os estudos da dimensão instrumental e do processo de legitimação de critérios de prova de evidência científica vêm se tornando objeto de interesse e pesquisa, pois revelam aspectos que eram deixados de lado pela abordagem clássica, preocupada sobretudo com a história das teorias científicas. Além desses aspectos, há outros vínculos entre ciência e cinema, 
dentre os quais aquele que vamos enfocar aqui: a formação do imaginário científico, pois, muito além de instrumento científico, o cinema foi um grande veículo de divulgação dos avanços da ciência e formação de uma audiência que entrevia nas telas o uso ilimitado de suas possibilidades. Enquanto aparato tecnológico, o cinema encarnou a modernidade através da velocidade, dos efeitos especiais, da urbanidade e da multidão de espectadores. $\mathrm{O}$ movimento era, naturalmente, um dos personagens favoritos, estrelado pelos novos artifícios tecnológicos: trens, motocicletas, bondes, carros, aviões.

Além de um dos símbolos e uma das inovações da modernidade, o cinema significou também um meio extraordinário de circulação do conhecimento, de difusão de novas experiências e valores culturais. Numa cultura inteiramente permeada pela expectativa de progresso científico e inovações tecnológicas é natural que os meios de comunicação projetem perspectivas semelhantes. Não apenas documentários e ficções científicas exprimem os conhecimentos desejados e os alcançados, mas até mesmo os dramas (profundos ou tolos) e as comédias revelam a penetração da ciência em nossa cultura. Isso faz dos filmes um ótimo material para análise da cultura e também para a compreensão da história da ciência. Seja através da reconstrução do passado ou do futuro do pretérito, os filmes nos possibilitam re-visitar os eventos ocorridos ou imaginados. As transposições e as vivências que a linguagem cinematográfica possibilitam são tão marcantes, que muitas vezes tornam-se referência de como a ciência e a técnica passam a percebidas por grande parte da sociedade. Mais do que aprendizagens derivadas das práticas educativas formais, as experiências vivenciadas nos filmes acabam compondo boa parte do arsenal simbólico através do qual a opinião pública passa a vislumbrar o alcance dos empreendimentos científicos e tecnológicos. Um exemplo caricato é o título da mostra de cinema que o Centro de Astrofísica da Harvard University, ninho de vários cientistas laureados, mantém há algum tempo: "Tudo que aprendi sobre ciência foi pelos filmes".

\section{O cinema na cultura brasileira}

Como em várias outras partes do mundo, o cinema se tornou uma das formas culturais mais significativas da sociedade brasileira do início do século XX, sobretudo no segundo terço (1930-1970). Enquanto nas primeiras décadas do século o filme cinematográfico era considerado "como uma atração de feira" (Kornis, 1992), ele logo transformou-se numa instância formativa poderosa, criando novas práticas e ritos urbanos. $\mathrm{O}$ cinema se tornou um amplo empreendimento industrial, que envolvia revistas, moda, produtos de beleza e discos, e infundia estilos de vida. 
Por volta dos anos 40, o hábito de ir ao cinema tornou-se de tal forma popular, que em cidades de grande porte, como Rio de Janeiro ou São Paulo, 80 por cento da população freqüentava as salas de exibição pelo menos uma vez por semana (Louro, 2000). É difícil acreditar em tal percentagem sem levar em conta que o vertiginoso crescimento demográfico das metrópoles brasileiras ocorreu a partir da década de 1950 e que, desde a década de 1960, o cinema foi progressivamente suplantado pela televisão. É preciso lembrar também que as salas de exibição eram bem maiores que as atuais, e que grande parte delas apresentava mudança diária na programação. Seja com for, sabe-se que salas de cinema foram sendo fechadas em toda parte. Na Inglaterra, por exemplo, o número de salas em 1970 era apenas a terça parte do que em 1950 (Jones, 1997). No Brasil havia 3.300 salas de exibição em 1975, número que foi reduzido à metade três décadas depois. Sobretudo nas cidades pequenas, salas de projeção foram desativadas e muitas se tornaram, sinal dos tempos, igrejas evangélicas.

A diminuição das salas de cine-teatro é um indicador expressivo, mas que esconde outras formas de veiculação dos filmes e interação entre os meios e as linguagens, pois, alternativamente às salas de cinema, os filmes são veiculados na programação televisiva ou em vídeos e DVDs e, mais recentemente, por meio de computadores. A legenda, que era um limitador da audiência de filmes estrangeiros, é substituída pela dublagem nas reapresentações em canal aberto. Além disso, o custo de ir ao cinema é bem maior hoje do que foi nos anos 40.

Sem dúvida, o cinema perdeu parte do glamour e da preponderância que possuía na vida social com a difusão da televisão. Porém, ainda detém um poder enorme e continua mobilizando cifras e audiências monumentais, para as quais segue vendendo estilos de vida, construindo e legitimando determinadas identidades sociais e desautorizando outras.

\section{Documentários e filmes educacionais}

1 "Cent ans de cinema scientifique", disponível em www.cndp.fr/ecole/ sciences/

objectif_science/pdf/

film_even/

lefilm_OS_114-

117.pdf, acessado em 2.6.2006.

Desde o início da difusão do 'cinema como diversão' , filmes foram sendo utilizados também como material didático, particularmente no ensino de ciências. Alguns países europeus testemunharam, no início da década de 1910, um grande florescimento de documentários e filmes escolares, enfocando sobretudo a zoologia e a botânica. Antes do início da Primeira Guerra Mundial, em 1914, centenas de documentários didáticos já haviam sido produzidos na França. ${ }^{1}$ Seqüências de imagens sobre a reprodução animal, sobre ciclos de vida das plantas, explosões vulcânicas ou sobre eclipses solares ajudavam a tornar currículos mais interessantes e explicações mais compreensíveis. 
No Brasil, em 1936, foi criado o Instituto Nacional do Cinema Educativo, sob a direção do antropólogo Roquette Pinto. Com a colaboração de cineastas como Humberto Mauro, o INCE realizou em torno de quatrocentos curtas-metragens até sua extinção em 1966, sendo quase um terço deles voltado para temas de educação científica e de divulgação de ciência e tecnologia (ver Galvão, 2004). Ao lado de iniciativas oficiais, havia também movimentos de pessoas engajadas na divulgação científica como um dos meios de modernização do país. Uma delas escreve no suplemento "Ciência para todos" do jornal A manhã, de 1948, sobre as vantagens do cinema educativo:

o professor, enquanto o filme corre, chama atenção dos alunos para os detalhes que julga mais importantes. E todos compreendem o fenômeno descrito porque podem 'ver' com seus próprios olhos a natureza em plena ação. $\mathrm{O}$ filme exerce desse modo o papel de denominador comum daquelas inteligências juvenis. Nivela-as pelo mesmo interesse no espetáculo e pelo poder que a imagem tem de tornar instantaneamente compreensíveis noções que as palavras nem sempre transmitem com fidelidade. (Laponte apud Esteves, 2006, p. 121)

Vários desses filmes iam muito além de meras lições e, com o desenvolvimento de novos recursos - cores, sons, filmadoras subaquáticas etc. - - , as imagens se tornaram ainda mais espetaculares. A beleza das filmagens do fundo do mar feitas por Jacques Cousteau (O mundo silencioso, 1953) e as intrigantes narrativas de Carl Sagan no seriado Cosmos tornaram-se conhecidas no mundo todo.

Mas, ainda que contenham imagens impressionantes e exemplos esclarecedores, filmes didáticos não mobilizam a emoção da mesma forma que as narrativas romanceadas. A exatidão sem dramaticidade é algo monótono. É com personagens e suas histórias que nos identificamos e nos projetamos. É nas tramas dessas narrativas que somos pegos. Fantasias e ficções falam de realidades que não aparecem noutros registros. Elas apresentam de uma forma não argumentativa, mas figurativa, as possibilidades da ciência e seus desdobramentos, permitindo uma visualização e uma vivência através da transposição que a linguagem cinematográfica possibilita e que se faz tão marcante.

É nas ficções científicas que primeiramente pensamos quando se fala de ciência no cinema. Mas ela nãoé, obviamente, o único gênero de filme a projetar imagens sobre a ciência, os cientistas ou as sociedades neles centrada. Filmes de aventuras, dramas, comédias e desenhos têm também sua parcela de contribuição na formação de estereótipos, modelos e expectativas que acabam por se constituir como referências comuns pelas quais a ciência e a técnica são perce- 
bidas por grande parte da sociedade, compondo assim o arsenal simbólico no qual a opinião pública vislumbra e discute os rumos e os limites dos empreendimentos científicos e tecnológicos.

\section{Ciência e imaginação}

A discussão sobre imagens e imaginação científica na história não é nova. O físico e historiador Gerald Holton desenvolveu trabalhos sobre a 'imaginação científica' com interessantes estudos sobre o papel de certas metáforas como modelos explicativos de uma determinada época. Por exemplo, o modelo do relógio, com seus sofisticados mecanismos e dispositivos embutidos para manutenção de uma regularidade, foi fundamental para a visão de mundo mecanicista, com a qual se tentava entender, na época de Descartes e Newton, o movimento dos astros celestes e a natureza física dos animais.

Em suas reflexões históricas, Laudan (1977) e Abrantes (1998) se valem da noção de 'imagens de ciência' para designar diferentes conjuntos de valores cognitivos, como métodos e critérios para a validação de teorias e experimentos ou mesmo para a delimitação dos objetivos da atividade científica. Como esses elementos que moldam a prática dos cientistas são normalmente assistemáticos e tácitos, eles são considerados não como teorias ou filosofias da ciência, mas como 'imagens de ciência'.

Essas noções de 'imaginação científica' e de 'imagens de ciência' correspondem em boa medida à noção de paradigma, que nos escritos de Kuhn tinha um sentido muito abrangente e variável. Ainda que na perspectiva socioconstrutivista essas abordagens sejam demasiado focadas nas idéias (pressupostos, noções, argumentos) e pouco nas práticas, e, sobretudo, não tenham, como os Estudos Culturais da Ciência, a pretensão de se posicionar criticamente frente às relações de poder envolvidas na construção do conhecimento científico, elas têm possibilitado um aprofundamento não apenas das discussões epistemológicas, mas também das análises das interrelações entre ciência e sociedade em contextos particulares.

As categorias de 'imaginação científica' ou de 'imagens de ciência' servem para se analisar a visão dos cientistas ou de aspirantes ao posto, ao passo que o 'imaginário científico' é algo mais amplo, que envolve várias formas de representação sobre a ciência. Acredito que o modelo de rede, proposto entre outros por Bruno Latour (2001), ajuda a compreender a ligação dessas representações com outras dimensões da ciência. Nesse modelo, deixa de fazer sentido a idéia de um centro de produção de conhecimento, a partir do qual o conhecimento seria aplicado, difundido ou consumido. É o conjunto de ligações que dá sustentação e força aos fios interligados na rede. A produção da ciência não é mais concebida como algo 
restrito à comunidade científica, e sim como o resultado da interação com outros fatores, como o da representação pública da ciência.

\section{Imaginário social e categorias correlatas}

Uma questão complicada a ser enfrentada por quem pretende investigar a formação das representações públicas sobre a ciência é a do papel da imaginação no campo da história. O imaginário é uma forma de realidade histórica, mas num sentido diferente do que habitualmente chamamos de realidade. Muitos historiadores mostraram que o verdadeiro evento não é somente um acontecimento que se passa no momento determinado, mas o que ele traz consigo e possibilita (Le Goff \& Cazenave, 1986).

O sistema simbólico de uma época ou grupo pode ser analisado a partir da perspectiva de sua funcionalidade social, por exemplo quando se consideram rituais como mecanismos de diferenciação de grupos ou como válvula de escape. Mas como os estudos sobre o imaginário têm apontado, faz-se importante perscrutar o simbólico independentemente de sua funcionalidade social, pois a riqueza de seu simbolismo ultrapassa suas funções. Isso não quer dizer que as sociedades constituem seus símbolos de forma inteiramente livre. Como observa Castoriadis, "todo simbolismo se edifica sobre as ruínas dos edifícios simbólicos precedentes, utilizando seus materiais, mesmo que seja só para preencher as fundações de novos templos" (1982, p. 147). As relações sociais exigem que o homem prolongue sua existência em imagens que faz de si mesmo e do outro, de seu passado e de seu futuro, o que pressupõe um trabalho permanente da imaginação, de interação com a razão e com as paixões e, em particular, a tradução de conceitos abstratos e valores em imagens.

Essa formulação se encontra bem próxima daquilo que Baczko desenvolve como imaginação social: um aspecto da vida social cujas particularidades se manifestam na diversidade dos seus produtos.

É assim que através dos seus imaginários sociais, uma coletividade designa a sua identidade; elabora uma certa representação de si; estabelece a distribuição dos papéis e das posições sociais; exprime e impõe crenças comuns; constrói uma espécie de código de bom comportamento ... de ordem em que cada elemento encontra o seu lugar, a sua identidade e a sua razão de ser. (Baczko, 1985, p. 309)

A dimensão formadora da imaginação social está implícita na percepção de que, ao designar identidades, distribuir papéis e exprimir crenças, não apenas informa acerca da realidade, mas, ao mesmo tempo, constitui um apelo à ação, um apelo a comportar-se de determinada maneira. O que se aproxima do conceito de ideologia desenvolvido por Paul Ricoeur (1977): uma motivação social 
que, mais do que um reflexo, é também justificação e projeto. A noção de ideologia, entretanto, está repleta de outros significantes e concepções, que tornam problemático seu uso como categoria de análise histórica. Ela ficou impregnada com o sentido de deslocamento da realidade, pressupondo uma realidade com uma densidade ontológica que apenas uma ciência revolucionária poderia alcançar. Justamente a pressuposição de tal ciência da realidade impediria qualquer esforço de uma compreensão histórica não determinista, que estivesse não desvelando leis da história, mas tentando entender como determinado conhecimento e supostas leis foram sendo construídos e difundidos. Desta maneira, os trabalhos que valorizam o imaginário como instância da realidade se conformam com a indeterminação e fragmentação da realidade, com a ausência de um referente para as representações do conhecimento, com a carência de uma visão de totalidade e com o caráter limitado (não absoluto) das interpretações.

Vale notar que as adjetivações das representações ou da imaginação como 'pública', 'coletiva' ou 'social', embora revelem um claro afastamento da noção do indivíduo como unidade cultural ou elemento fundador da linguagem, da percepção das práticas ou conhecimentos, podem dar a entender uma ausência de indistinção interna entre estes coletivos, como se eles não fossem compostos por classes ou grupos com interesses divergentes, com diferentes forças e condições. Mas não se trata disso. A questão é justamente não adotar esquemas de estruturas sociais descontextualizados, antes de se compreender a questão e suas tensões internas. O imaginário é construído por diferentes concepções de grupos sociais distintos, e é nessas diferenças que se há de entender as tensões de interesses. As diferenças não correspondem diretamente às demarcações sociais estabelecidas previamente. Por isso se considera que "o desafio hoje lançado aos historiadores é ligar a construção discursiva do social à construção social dos discursos" (Chartier apud Falcon, 2002, p. 89).

A noção de que qualquer prática é normativa e interfere na maneira como os outros percebem e reafirmam a cultura, muitas vezes oculta a preponderância de certos grupos sociais, de meios de difusão e de legitimação. Dissimula-se o fato de que, dependendo das épocas e lugares umas perspectivas, certos discursos e instituições se fazem ouvir mais que outros. Mas o conhecimento de estruturas de poder num contexto e sua transposição para outros despreza o fato de que o exercício de poderes, ainda quando institucionalizados, depende de atualizações, rearranjos e negociações.

Embora tenha interessado mais aos estudiosos da psicologia social do que aos historiadores, a noção de representação social desenvolvida por Moscovici (1978) é também de grande relevância para a discussão sobre o processo de formação e de difusão do imaginário científico. A representação social é ali concebida como uma 
intermediação entre conceito e percepção, algo que estrutura e orienta as condutas sociais. Ela funcionaria como ancoragem das diferentes modalidades de comunicação. Assim, as representações sociais são pesquisadas como princípios organizadores (hierarquizações, dicotomia) ou princípios geradores de tomadas de posição, ligados a inserções específicas em um conjunto de relações sociais. Tal concepção é valiosa para a psicologia social e a comunicação social que procuram, a partir de pesquisas empíricas em grupos focais, por exemplo, compreender processos de formação de escolhas e meios de inferir comportamentos. Mas elas podem também ser de grande serventia teórica e metodológica para historiadores das ciências na compreensão das percepções e da formação de práticas de contextos passados.

Como se pode ver essas categorias de 'representação social' ou 'representação cultural', 'imaginário' ou 'imaginação social' , 'ideologia', 'mentalidade' e 'opinião pública' têm várias versões que se interpõem. É fácil perceber a proximidade entre suas abordagens e defender uma possível complementaridade entre seus campos de estudo e perspectivas, mas é difícil estabelecer fronteiras ou precisar onde uma preenche a lacuna da outra.

\section{A ciência nos filmes}

É muito comum tratarmos de autoria de filmes, pela diferença que um específico diretor, produtor, roteirista ou diretor de arte pode fazer no produto final. Mas para analise de noções gerais como as representações de ciência ou estereótipos de cientistas a construção é, em geral, coletiva. Filmes expressam o olhar não só das pessoas envolvidas em sua montagem, mas, indiretamente, revelam o imaginário de seus espectadores, pois antes mesmo de vir a contribuir na formação e reforço de hábitos culturais, a produção de um determinado filme leva em conta a visão de seu público alvo, seu universo de referências, conhecimentos e expectativas. Nesse sentido revelam, mais do que outras produções artísticas como um livro ou pintura, o olhar de uma época ou de uma sociedade.

Como já ressaltou um dos precursores da utilização do cinema como fonte histórica, Marc Ferro (1992), o princípio de organização de filmes é dramático e estético. Eles dependem da beleza dos planos e nas guinadas da narrativa e do suspense. Por isso, uma boa análise de filmes deveria levar em conta as estruturas da linguagem cinematográfica e a composição de seus vários elementos. Todavia, nosso objetivo aqui é a discussão das concepções de ciência e de cientista neles contidos, e, portanto, se restringe aos conteúdos dos filmes. Mesmo assim, é importante ressaltar que o enfoque sobre a ciência tende a variar entre os diferentes gêneros de filmes. 
Dada a ampla gama de filmes históricos, Nova (1997) procurou traçar algumas distinções que devem ser consideradas, pois sugerem tratamentos diferenciados para quem pretende desenvolver análises da perspectiva histórica. Inspirado em sua classificação, procurei aqui esboçar uma tipificação filmográfica que pode ajudar na análise das representações da ciência e do cientista. São eles:

1. Documentários, cuja narrativa não envolve construção de personagens humanos, e ou nos quais as características didáticas do roteiro prevalecem sobre os elementos de dramáticos. A maior parte deles é de curta ou média metragem, e poucos são produzidos visando exibição comercial em cinemas.

2. Reconstruções de casos reais de descobertas (O óleo de Lorenzo; $E$ a vida continua) e debates científicos ( $O$ vento será sua herança; Tempo de despertar), envolvendo fatos reais e personagens históricos.

3. Filmes biográficos de personagens célebres da história da ciência, como Giordano Bruno, Marie Curie, Freud além da alma, ou de pessoas menos conhecidas mas consideradas importantes, como o matemático John Nash em Uma mente brilhante e o médico que desenvolveu o uso de tinturas para exame de tecidos animais em Avida do Dr. Ehrlich.

4. Filmes em que cientistas históricos estão envoltos na trama ficcional. Ainda que o enredo tenha outro foco, os personagens centrais contracenam com figuras históricas, como Carl Jung em Jornada da alma, ainda que com o intuito burlesco, como Einstein em Teoria do amor.

5. Filmes cujos enredos ilustram teorias, como a psico-neurologia de Henri Laborit em Meu tio da América, ou debates sobre a ciência, seus pressupostos e implicações, como O ponto de mutação e Quem somos nós.

6. Filmes que tratam da ciência no sentido amplo de visão de mundo, seja retratando o embate da lógica racional frente a outros padrões culturais (O nome da rosa; Kaspar Hauser; Greystoke: a lenda de Tarzan), seja contrastando a perspectiva científica com outros modelos cognitivos, como a magia ou o senso comum ( $O$ inglês que subiu a colina e desceu a montanha; Narradores de Javé).

7. Filmes em que a ciência é o pano de fundo. Como a ciência passou a ser um dos elementos centrais da cultura do século $X X$, seus elementos, produtos e valores aparecem em diversas retratações da vida social, como nas histórias sobre desafios tecnológicos reais (Os eleitos; O aviador) ou imaginários (Até o fim do mundo), filmes policiais, de aventura (Indiana Jones) ou de julgamentos.

8. Ficções científicas propriamente ditas, em que a ciência parece ser a personagem central. Aqui a dimensão ficcional é evidente, 
pois, ainda que verossímeis, essas narrativas quase nunca são factíveis, ou seja, são fantasiosas (irreais) ou irrealizáveis nas atuais condições do conhecimento. Sejam elas otimistas (De volta ao futuro) ou sombrias e ameaçadoras (1984; Brazil: o filme; Fahrenheit 451), elas representam uma espécie de experimento mental sobre os possíveis usos e implicações da ciência e da tecnologia. Há vários graus de sofisticação no enredo, nos diálogos e nas imagens: as narrativas derivadas do romance científico de Poe, Wells e Júlio Verne costumavam ser mais elaboradas que aquelas derivadas de revistas e quadrinhos feitos em série (Flash Gordon, 1936, 1938; Buck Rogers, 1939). Essas diferenciações entre utopias otimistas versus distopias pessimistas e literatura versus seriados são apenas algumas das subdivisões possíveis dos filmes de ficção científica, e, como se pode notar, tais oposições não têm fronteiras muito nítidas entre si.

Aliás, esta observação da imprecisão é extensível ao conjunto da tipificação esboçada, que contém lacunas e superposições. Por exemplo, as reconstruções de casos reais de descobertas (segundo tipo) envolvem personagens reais notáveis. Todavia, como o foco ali não é biográfico, essas narrativas não devem ser confundidas com os chamados biopics (abreviação de biographical pictures) que apresentamos como o terceiro tipo. A diferença entre o terceiro e o quarto tipos também é tênue: ainda que no terceiro grupo a trama seja ficcional, a caracterização do cientista que aparece envolvido pode conter mais do que uma inspiração na personagem histórica e retratar de maneira fidedigna acontecimentos históricos reais. Entretanto, mesmo não sendo meticulosa, essa classificação geral pode ajudar a dimensionar lacunas e perceber melhor as especificidades dos casos dos que não se encaixam bem nesses oito grupos.

Todos esses tipos de filmes são históricos, tanto no sentido de refletirem o olhar de uma sociedade ou um grupo de uma determinada época, como no sentido de serem agente histórico, enquanto elemento formador do imaginário social. Em ambos os sentidos, podem contribuir para a compreensão da história da ciência. Como muitos clássicos dessa filmografia foram sendo refilmados - por exemplo, Frankenstein (1931 e 1994), A máquina do tempo (1960 e 1996), A ilha do doutor Moreau (1977 e 1996), A mosca (1958 e 1986), Fluber (1963 e 1997) -, acredito que uma boa estratégia para o estudo dos imaginários de diferentes épocas e de suas transformações é a análise comparativa das distintas versões da mesma história, filmadas em épocas diferentes.

A quantidade de filmes de ficção científica é bem maior do que a dos filmes de biografias de cientistas, ou narrativas que encenam teorias. Ainda que com origens diferentes, o que lhes imprimiu algumas características próprias, as ficções científicas têm traços 
comuns, que o contraste com outros tipos de ficções fabulosas ajuda a realçar. Em histórias populares e arquetípicas, como as de vampiros, sabemos ou acreditamos prontamente em fenômenos inexplicáveis. Por exemplo, fantasmas não aparecem em espelhos e vampiros não gostam de alho. O porquê desses e de outros conhecimentos não interessa ali. Mas na ficção científica, mesmo quando ela se vale de imagens míticas, estas são exploradas de forma tal que as razões científicas possam ser apresentadas. Assim como nas óperas os acontecimentos parecem ser pretexto para se entoar uma ária, nesses filmes as situações projetadas servem para encenação de especulações científicas. A excitação que geram em boa parte da audiência advém da sofisticação das hipóteses, da especulação de seus possíveis desdobramentos.

O fantástico que vem à tela deve ser ao menos admissível da perspectiva científica, como se tudo que parece misterioso tivesse uma explicação racional. É claro que nem sempre conseguimos acompanhar suas explicações, pois elas se apóiam em teorias que nada têm de óbvias ou factíveis, mas devem parecer plausíveis. Um dos recursos para tornar as especulações aceitáveis é o uso de terminologias sofisticadas - "endobiose de matéria auto-criadora" (Guerra dos mundos) "criptozoologia" (20 mil léguas submarinas), "mutações atávicas em replicantes" (Blade Runner), "interpolação de interlock" (Contatos imediatos), "simulação neurointerativa" (Matrix).

\section{Imagens da ciência no cinema}

Narrativas romanceadas quase sempre tecem casos particulares, personagens numa situação específica. Mesmo quando discutem teorias, elas envolvem elementos dramáticos e relações entre pessoas que estão ambientadas e têm caracteres físicos e psicológicos determinados. Assim, ao abranger os contextos de descoberta, as práticas sociais de construção de consensos e as formas de circulação dos conhecimentos a representação da ciência no cinema quase sempre abarca elementos que a historiografia da ciência tradicional considerava como extra-científicos.

Um segundo aspecto a ser notado, e que está vinculado a esse primeiro, é a conjunção da ciência com a tecnologia. Uma vez que a ciência é abordada em seus possíveis usos, torna-se difícil percebêla como algo distinto da tecnologia. Mesmo os filmes que narram o surgimento de teorias ou seqüências de experimentos científicos (como Pasteur e Thomas Edison) vão buscar torná-las significativas para o grande público ressaltando suas relações com a vida cotidiana. E quase sempre a relevância social, e não tanto as exigências epistemológicas como a coerência, que sobressai nas encenações.

Apesar da flutuação dos significados e da ambivalência das imagens, a ciência é geralmente retratada no cinema como civilizadora, 
progressiva, racional, e neutra. O conhecimento científico é visto como algo apolítico, não dogmático, inteiramente fundamentado e comprovado, mas perigoso. Vale observar como mesmo as distopias, em que o futuro é visto como sombrio, e as representações negativas do cientista não implicam necessariamente desencanto com a ciência. O perigo residiria no mau uso da ciência, e ela permaneceria neutra e em aperfeiçoamento. Assim, a questão estaria em evitar que ela fosse instrumentalizada por pessoas egoístas e malvadas. A saída comumente sugerida é o desenvolvimento mais controlado da ciência.

A concepção de como a ciência funciona na prática é outro aspecto que vai sendo difundido através de filmes. Uma vez que a ciência que se aprende na escola não privilegia essa dimensão, os filmes se tornam um dos principais veículos de formação dessas noções. Por exemplo, muitos filmes de espionagem ajudaram a difundir a idéia de que a produção da bomba nuclear dependia da obtenção de uma fórmula secreta. Esta poderia ser uma equação complexa, mas algo reproduzível num pedaço de papel ou na fotografia de um plano. Fórmulas que poderiam facilmente cair nas mãos dos inimigos. Assim sendo, seus detentores devem ser bem cuidados, mas vigiados. Logo após o lançamento das bombas atômicas em Hiroxima e Nagasaki em agosto de 1945, os físicos teóricos se tornaram grande celebridades nos Estados Unidos e, pelas mesmas razões, atraíram as atenções do macarthismo, alguns anos depois (Kaiser, 2005). Pouco adiantaram as explicações públicas de que o projeto Manhattan era um empreendimento que envolvia milhares de pessoas, inteligências e habilidades de diversos tipos, ou que o domínio da energia atômica, como o de tantas outras tecnologias, é um processo que abarca todo um sistema de organização, com aparatos, mecanismos, conhecimentos tácitos e que, portanto, os físicos teóricos não teriam mais responsabilidade do que outros especialistas e técnicos envolvidos. Os meios de comunicação continuaram a tratar da ciência, preponderantemente, como o produto de descobertas geniais, de mentes inspiradas, considerando os produtos tecnológicos como simples aplicação das descobertas teóricas.

A confiança ou a suspeita nos cientistas, o entusiasmo ou a desconfiança no desenvolvimento da ciência é algo que tem variado e deve ser estudado em sua interação com o contexto de produção e recepção desses filmes e em suas relações com outras manifestações culturais.

Vários estudos têm sido realizados visando a um melhor conhecimento das imagens dos cientistas. Em From Faust to Strangelove, Haynes (1994) sintetiza alguns tipos recorrentes na literatura ocidental. Os mais representativos são: 
- o do cientista diabólico, que pretende reverter os limites humanos impostos pelo Criador;

- o professor, bem intencionado, mas ingênuo, que geralmente é enganado e perde controle da aplicação de seu conhecimento;

- o herói aventureiro, que se arrisca a qualquer perigo e, como um bom detetive, desvenda quebra-cabeças insolúveis;

- o idealista, salvador da humanidade e planejador de sociedades utópicas;

- o cientista como inventor, genial, mas com desequilíbrios emocionais.

Embora o universo de Haynes seja o da literatura e não propriamente o do cinema, podemos facilmente reconhecer esses estereótipos nos filmes. Além do fato de grande parte dos enredos e personagens do cinema serem transposição de livros clássicos (Fausto, Frankenstein, O médico e o monstro, A guerra dos mundos), ou que se tornaram conhecidos a partir do sucesso dos filmes neles inspirados (como Metrópolis e Blade Runner), as representações da ciência moderna, de suas possibilidades e de seus agentes têm uma grande persistência que se manifesta em diversas expressões culturais.

Esses estereótipos podem ser ressignificados e desdobrados em outros, que, embora menos recorrentes, são especialmente reveladores de um contexto histórico específico. E o que se vê pelos resultados da análise que Jones (1997) faz do cinema inglês do pósguerra. $\mathrm{O}$ fato de ele restringir sua análise a um determinado tipo de produção (filmes ingleses de grande circulação, deixando de lado as ficções científicas, ou seja, filmes de ação, romance, guerra e suspense que têm cientistas envolvidos na trama) e a um período mais delimitado (1945-1970) que os quatro séculos cobertos por Haynes, possibilitou a Jones perceber melhor as variações dos estereótipos e suas ligações com o contexto de produção e recepção. Jones os agrupa em três categorias: a dos cientistas criadores (que ele chama de 'artistas', mas que se assemelham ao cientista como inventor genial conjugado com o descrito por Haynes), a dos cientistas destruidores e a dos boffins. A primeira e a segunda categoria, a dos cientistas que, sem querer, acabam gerando danos as outras pessoas e a eles mesmos, são bem conhecidas e perpassam com pequenas variações diferentes contextos. A construção e os ecos dessas duas representações são de longa duração, diferentemente da terceira, que ele analisa mais detalhadamente.

Boffin é um termo britânico para o cientista-pesquisador que trabalha para o Estado e quase sempre tem problemas com a burocracia. Suas principais características são a obsessão, uma propensão ao heroísmo, um tom professoral (adora dar explicações) e pouca sociabilidade. Além de ambivalentes, esses traços podem estar 
presentes também em outras representações típicas de cientistas, mas que, conjugados em personagens 'pesquisadores a serviço do Estado', permitem uma melhor compreensão das flutuações no apoio dos britânicos ao empreendimento científico naquele período. As flutuações no apoio devem ser consideradas no duplo sentido do cinema como reflexo e como agente formador: no primeiro sentido, os filmes ecoam as percepções sociais da época em que foram produzidos e, no segundo, suas projeções reforçam certas imagens e noções nos espectadores. As análises e interpretações do primeiro sentido são bem mais palpáveis que as do segundo. Os boffins dos filmes feitos nos primeiros anos do pós-guerra têm uma positividade (lealdade, disciplina) e inspiram uma confiança que vai sendo progressivamente dissipada até os anos 70. A variação no caráter dos boffins manifesta o distanciamento temporal da Segunda Guerra Mundial e da percepção da ciência como decisiva para a vitória. A desconfiança frente aos usos da ciência e ao papel social de seus representantes se acentua especialmente a partir da contestação cultural da década de 1960.

Ainda que pouco palpável, é na análise do papel do cinema na formação do imaginário social acerca da ciência que, a meu ver, reside o maior desafio para compreensão da atitude do público sobre a ciência. Evidentemente, essa dimensão formadora não pode ser vista como algo independente da força exercida pelos outros meios de comunicação. Mesmo assim, e até mesmo para uma análise mais complexa envolvendo o conjunto dos meios de comunicação, algumas particularidades do poder formador do cinema podem ser pensadas, e pesquisas específicas podem ir sendo desenvolvidas.

\section{Dificuldade em avaliar repercussão e influência no imaginário}

Apesar de a estatística de audiência fornecer algumas pistas, a influência no imaginário não pode, obviamente, ser reduzida a números de filmes ou de suas bilheterias. Há filmes que tiveram enorme sucesso de público, mas que depois foram praticamente esquecidos, enquanto outros viraram cult e se tornam referências para outras gerações ou para círculos com maior peso na formação de opinião pública, como jornalistas, artistas e professores.

A não ser em casos especiais, é muito difícil avaliar a real repercussão ou precisar a influência de diferentes eventos e criações na cultura de uma determinada sociedade ou época. Um bom exemplo das dificuldades na determinação das influências culturais nos comportamentos é retratada no documentário Tiros em Columbine. Tentando deslindar o que havia levado dois estudantes a fazerem uma matança em sua escola, o filme explora diferentes hipóteses. Para a 
sociedade local a explicação estava no cantor de rock (Marilyn Manson), autor das músicas que os jovens assassinos ouviam e que incitavam a violência; já os pedagogos a imputavam à programação da televisão, tanto nos noticiários quanto nos filmes; um ex-estudante de Columbine apontava a entediante e opressiva cultura escolar como a principal causa da rebeldia; o diretor do filme, Michael Moore, sugeria que os atos bélicos do presidente da República e da associação de amantes das armas (National Rifle Association) teriam uma influência bem maior, mas indagava sobre a preponderância de outras práticas, como o boliche que os jovens jogaram logo antes de ir à escola metralhar seus colegas. Ainda que advindos de casos policiais, as discussões sobre os mecanismos de formação de comportamentos podem ajudar a interpretação das representações sociais ao longo da história. Apesar das dificuldades, interessa aos historiadores da ciência entender o processo de formação das noções, valores, expectativas acerca da ciência e como essas representações se articulam com os outros aspetos do empreendimento científico.

\section{Conclusão}

As questões levantadas e as observações feitas nas páginas precedentes servem mais para revelar dificuldades e desafios do que propriamente para se extraírem conclusões.

A persistência de embaraços teórico-metodológicos é uma delas, que reflete nas análises, ainda insuficientes, dos filmes. Há também dificuldades no dimensionamento dos filmes como formadores do imaginário social sobre a ciência. Essas limitações podem ser encaradas como desafios, aos quais se acrescentam outros, como a necessidade de se analisar o universo dos documentários para uma melhor caracterização do imaginário científicos no cinema e sua repercussão. Como se pôde perceber, as representações da ciência e dos cientistas no cinema são variadas, e suas significações dependem do contexto, que análises mais aprofundadas devem também levar em conta.

Este estudo inicial mostrou ainda que as imagens e representações da ciência e seus representantes nos filmes são flutuantes e podem ser discrepantes. Cientistas são, por exemplo, estereotipados simultaneamente como astuciosos e ingênuos, humildes e prepotentes. Na análise do imaginário científico, entretanto, a coexistência de representações opostas não significa necessariamente dissonância. Num interessante livro sobre a ciência na televisão, Siqueira nos mostra, com base nas teorias de Barthes e Bakhtin, como o imaginário é formado por diferentes textos culturais, e como dentro de um mesmo texto estão presentes discursos nem sempre convergentes. Não existe, portanto, um discurso sobre a ciência, mas 
sim um processo polifônico de construção de discursos, ou, nas palavras de Barthes, "uma trança de diferentes vozes, de códigos múltiplos, ao mesmo tempo entrelaçados e inacabados. Uma narrativa não é um espaço tabular, uma estrutura plana, é um volume, uma estereofonia" (Barthes apud Siqueira, 1998, p. 47).

Para o historiador interessado no desenvolvimento da ciência é fundamental compreender esse processo de construção de discursos e sua interação com outros aspectos da prática científica.

\section{REFERÊNCIAS BIBLIOGRÁFICAS}

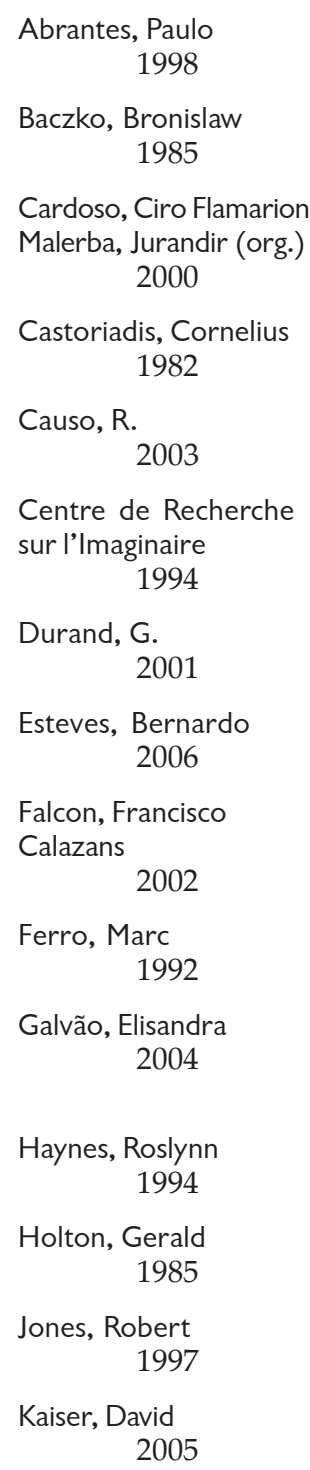

Imagens da natureza, imagens de ciência. Campinas: Papirus.

A imaginação social. In: Enciclopedia Einaudi. Lisboa: Imprensa Nacional. p. 283-347.

Representações: contribuição a um debate transdisciplinar. Campinas: Papirus.

A instituição imaginária da sociedade. Rio de Janeiro: Paz e Terra.

Ficção científica, fantasia e horror no Brasil, 1875- 1950.

Belo Horizonte: Ed. UFMG.

Ciência e imaginário.

Brasília: Ed. UnB.

O imaginário.

São Paulo: Difel.

Domingo é dia de ciência: história de um suplemento dos anos pós-guerra. Rio de Janeiro: Azougue.

História cultural: uma nova visão sobre a sociedade e a cultura. Rio de Janeiro: Campus.

Cinema e história.

Rio de Janeiro: Paz e Terra.

A ciência vai ao cinema: uma análise dos filmes educativos e de divulgação científica do INCE. Dissertação de Mestrado. Departamento de Bioquímica - Universidade Federal do Rio de Janeiro.

From Faust to Strangelove: representations of the scientist in western literature. Baltimore: Johns Hopkins University Press.

La imaginación científica.

México: Fundo de Cultura Economica.

The Boffin: a stereotype of scientists in post-war British films (1945-1970). Public Understanding of Science, v. 6, p. 31-48.

The atomic secret in red hands? American suspicions of theoretical physicists during the Early Cold War. Representations, v. 90, p. 28-60. 
Kormis, Mônica

1992

Latour, Bruno 2001

Laudan, Larry 1977

Le Goff, J.;

Cazenave, $M$. 1986

Louro, Guacira 2000

Moscovici, Serge 1978

Nova, Cristiane 1997

Oliveira, Bernardo J. (org.) 2005

Pastre, Dominique 1996

Ricoeur, Paul 1977

Siqueira, Denise 1998
História e cinema: um debate metodológico.

Estudos históricos, v. 5, n. 10, p. 237-50.

A esperança de Pandora.

Bauru (SP): Edusc.

Progress and its problems: toward a theory of scientific growth. Berkeley: University of California Press.

Histoire et imaginaire.

Paris: Poesis.

O cinema como pedagogia. In: Lopes, Eliane; Faria Filho, Luciano; Veiga, Cynthia (org.) 500 anos de educação no Brasil. Belo Horizonte: Autêntica. p. 433-66.

A representação social da psicanálise.

Rio de Janeiro: Zahar.

O cinema e o conhecimento da história.

Olho da história, Salvador, n. 3, p. 217-33.

História da ciência no cinema.

Belo Horizonte: Argvmentvm.

Por uma nova história social e cultural das ciências: novas definições, novos objetos, novas abordagens. Caderno IG/Unicamp, Campinas, v. 6, n. 1, p. 3-47.

Interpretações e ideologias.

Rio de Janeiro: Francisco Alves.

A ciência na televisão: mito, ritual e espetáculo.

São Paulo: Annablume.

Recebido para publicação em outubro de 2005.

Aprovado para publicação em fevereiro de 2006. 